Running head: Teachers' Attitude to Inclusion Scale

\title{
Psychometric properties of the revised Teachers' Attitude towards Inclusion
}

\section{Scale (TAIS)}

Jeremy Monsen ${ }^{1}$, Donna Ewing ${ }^{2}$ and James Boyle ${ }^{3}$

${ }^{1}$ East London Consortium of Educational Psychologists, Education Support Services Children and Young People Service Waltham Forest Council Summerfield Centre, 99 Leyton Green Road, London E10 6DB, UK e-mail: jeremy.monsen@virgin.net

${ }^{2}$ School of Psychology, University of Sussex, Pevensey Building, Falmer, Brighton BN1 9QH, UK e-mail: ewing.donna@gmail.com

${ }^{3}$ School of Psychological Sciences and Health, University of Strathclyde, 40 George Street, Glasgow G1 1QE, UK

e-mail: j.boyle@strath.ac.uk

May 2014

* All correspondence concerning this article should be addressed to Donna Ewing, University of Sussex, School of Psychology, Pevensey Building, Falmer, Brighton, England, BN1 9QH Email: ewing.donna@gmail.com; Tel: 07716307610 


\section{Abstract}

This paper presents the psychometric properties of a questionnaire measure which updates and extends Larrivee and Cook's (1979) Opinions Relative to Mainstreaming Scale in terms of structure, terminology and language. The revised scale was tested using a sample of 106 teachers based in inclusive mainstream schools. Using Principal Component Analysis, a four-factor structure was found for the 'attitudes towards inclusion' section of the revised scale: (i) problems of inclusion of SEN children in mainstream classes; (ii) social benefits for all of the inclusion of SEN pupils in mainstream classes; (iii) implications of inclusion for teaching practice; and (iv) implications for addressing the needs of children with SEN. Moderate to good reliability was found for these components (Cronbach's $\alpha:$.76 - .86). In conclusion, the updated and revised Teachers' Attitude to Inclusion Scale (TAIS) shows promise as being a reliable and valid measure for both research and applied purposes.

Keywords: teacher attitude; inclusive education; special educational needs; scale development 
Teacher attitudes and beliefs have a powerful influence on how successfully inclusive educational practices are implemented (Forlin, Keen, \& Barrett, 2008), with negative attitudes towards inclusion inhibiting the success of the implementation of inclusive education (Gibb, Tunbridge, Chua, \& Frederickson, 2007). Classroom learning environment and teaching approach have been found to be affected by the attitudes teachers espouse (Grieve, 2009; Ross-Hill, 2009). Teachers' attitudes towards inclusion may also be influenced by the teachers' opinions about their personal expertise or knowledge to include children with special educational needs (SEN) within their classroom (Avramidis, Bayliss \& Burden, 2000; Forlin et al., 2008; Gibb et al., 2007; Goodman \& Burton, 2010), as well as whether they feel as though they have resources available (Goodman \& Burton, 2010), or manage the resources available effectively (DfES, 2004).

The Opinions Relative to Mainstreaming Scale (ORMS) was developed by Larrivee and Cook (1979) to investigate classroom teachers' attitudes towards mainstreaming children and young people with special educational needs (SEN). This measure was developed in response to the legal, financial and social pressures of the time that children and young people with SEN should be included and educated within mainstream school settings. In addition to teacher attitudes, Larrivee and Cook (1979) considered seven variables expected to have an impact on teachers' attitude: grade level taught; classroom size; school size; type of school setting; teacher success with SEN pupils; level of administrative support received; and availability of support services. Larrivee and Cook (1979) found that perception of success of inclusion and that the level and availability of support significantly and positively affected teachers' attitudes towards including children with SEN.

\section{Why the ORMS is no longer suitable}

Since the development of the ORMS, there have been many significant changes in government policies in England regarding inclusive education (e.g., DfES, 2001; DfES, 2003; DfES, 2004; DfES, 2006; DCSF, 2010; UNESCO, 1994). Initially, children and young people with special educational needs were segregated from mainstream schooling. Policy changes led to the integration or co- 
location of children and young people within mainstream schools, and later moved towards full inclusion where pupils with SEN receive equal opportunities to normally functioning peers (Frederickson \& Cline, 2010; Janney \& Snell, 2006). Other researchers have also identified the need to adapt the language of the ORMs in accordance with these policy changes. For instance, Antonak and Larrivee (1995) and Beattie, Anderson and Antonak (1997) updated the wording 'handicapped' and 'special-needs' to 'disability', and updated the wording 'mainstreaming' to 'integration' in accordance with the policies around at that time. However, due to further changes in policy, the term 'integration' is no longer appropriate and requires adapting to the term 'inclusion' to represent the change from simply being present in the classroom to being fully included within the mainstream class. Avramidis, Bayliss and Burden (2000) similarly felt that the ORMS required updating, and adapted the measure for their study, using terms of 'inclusion' rather than 'mainstreaming' or 'integration'. However, Avramidis et al. (2000) only adopted 12 of the original 30 items, whereas the current study proposes that each of the original items should be included in the updated version.

Current government policies focus on parental choice as to whether their child with SEN attends a mainstream or special school (DfE, 2011). There therefore remains a need for a measure of teacher attitude towards inclusion for those children with SEN placed within mainstream schooling. It is surprising that there are very few measures available that tap into teacher attitudes towards this important aspect of applied practice. Considering the vast changes in policy and terminology since the Opinions Relative to Mainstreaming Scale was first published in 1979 it seemed appropriate to systematically update and revise it.

\section{Current Study}

The current paper presents an updated version of the Opinions Relative to Mainstreaming. In addition to updating the terminology to represent that of current policy, the revised Teacher Attitudes to Inclusion Scale extends the original questionnaire to include an assessment of teachers' willingness to include different types of SEN within their classroom, as some research suggests that 
children with certain difficulties may be more difficult to include within the mainstream classroom compared to others (Evans \& Lunt, 2002; Visser, Cole \& Daniels, 2003; Visser \& Stokes, 2003). Questions relating to teachers' perceived adequacy of support have also been added to the TAIS based on findings to suggest that these may play an important role in teachers' attitudes towards inclusion (for example, Goodman \& Burton, 2010). Similarly, perceptions of expertise to work with children with SEN have been found to impact teacher's attitudes towards inclusion (for example, Avramidis, Bayliss \& Burden, 2000; Forlin et al., 2008; Gibb et al., 2007; Goodman \& Burton, 2010), and so the demographic section of the questionnaire has been extended to cover this. This updated and extended version has been used successfully within two large scale studies considering the effects of teachers' attitudes towards inclusion on classroom learning environments, using schools based in New Zealand (Monsen \& Frederickson, 2004) and England (Monsen, Ewing \& Kwoka, 2013). The current paper presents the psychometric properties of this updated and extended version.

\section{Method}

\section{Participants}

A random sample of inclusive mainstream schools from the South East of England were invited to take part, with 121 schools initially contacted, and responses received from 106 teachers (across approximately half of these schools). Incomplete responses were discarded, leaving a sample of 95 teachers ( 73 females; 21 males; and 1 undisclosed). The mean age of teachers was 40 years old, and teachers had a mean of 12 years of teaching experience. At the time of testing, teachers taught Year Groups 1 to 6 , and had class sizes of 10 to 35 pupils (mean $=29$ pupils). Teachers had a range of qualifications: teacher's certificate (23.7\%), Post-Graduate Certificate in Education (PGCE) (24.7\%), university degree $(38.7 \%)$, studying, $(1.1 \%)$, or other $(5.4 \%)$. The participants in this study were not necessarily teachers of students with special educational needs in particular, but may have had children with SEN within their class groups - indeed, $97.8 \%$ of the teachers reported having a child with SEN within their class. 
Please note, additional data was also collected from 2,556 pupils which is reported in another paper considering the effects of teacher attitudes towards inclusion on classroom learning environments (see Monsen, Ewing \& Kwoka, 2013).

\section{Measures}

Teacher Attitude to Inclusion Scale (TAIS): The TAIS is a questionnaire based on Larrivee and Cook's (1979) Opinions Relative to Mainstreaming Scale (ORMS). Adaptations to the ORMS have been made, and the language modified according to current inclusion terminology, as well as by adapting American spellings and wording. The TAIS includes four sections, each of which are scored using an 8-point scale. Each of the sections are discussed in turn below.

Section 1: Demographics. This is similar to the first section of Larrivee and Cook's (1979) ORMS and collects information about class level taught and the number of children in the class. The wording from Larrivee and Cook's (1979) version was adapted from American to British Standard English. As an extension to the demographic information collected by the ORMS, this scale collects further demographic information about the teachers by including questions about the age and gender of the teacher, years of teaching experience, qualifications, and level of contact with SEN children and young people.

Section 2: Willingness to Include. This section is an addition to Larrivee and Cook's

ORMS, and aimed to identify whether teachers have greater or lesser willingness to include children and young people with different difficulties, including physical (such as hearing or visual), behavioural, social or emotional, or learning difficulties. Teachers used an 8-point Likert-type scale to rate their willingness to include pupils with each difficulty within their class.

Section 3: Adequacy of Support. Larrivee and Cook's (1979) ORMS included two variables to assess the adequacy of support experienced by teachers: 'level of administrative support received' and 'availability of supportive services'. However, as these variables were relatively broad, this scale adapted and extended these to ask teachers specifically about the adequacy of support they had 
received from a variety of sources, including withdrawal room facilities, learning support staff, educational/school psychologists, appropriate teaching materials, parent/carer helpers, school advisors, behavioural support teachers, classroom assistance, general school support, and support from colleagues. Teachers were asked to rate their perceived adequacy of support on an 8-point Likert-type scale, with higher scores indicating greater perceived adequacy of support.

Section 4: Attitudes towards Inclusion: This section is closely based on the second section of Larrivee and Cook's (1979) ORMS, and samples teacher attitudes to the concept of 'inclusion'. This section comprises a 30-item questionnaire designed to measure teachers' general attitudes towards including SEN children and young people within mainstream schools. The ORMS had a five factor structure, including factors of: "general philosophy of mainstreaming", "classroom behaviour of special needs children", "perceived ability to teach the special needs child", "classroom management with special needs children", and "academic and social growth of the special needs child" (Larrivee, 1982). A number of adaptations from the original ORMS were made, although it remained conceptually the same. Modifications included adapting American spellings and wording, updating now out-of-date terminology, and implementing an 8-point rather than 5-point Likert-type scale for consistency with the other sections of the TAIS. Examples of the out-of-date terminology include referring to children with SEN as 'handicapped' and non-SEN children as 'normal', which are not in concordance with current terminology. In addition, terms of 'mainstreaming' and 'integration' were replaced with the term 'inclusion' in accordance with terminology used within current government policies (e.g. DCSF, 2010). Teachers rated their agreement with each statement ranging from 'strongly agree' to 'strongly disagree'. As in Larrivee and Cook's (1979) original questionnaire, item response bias was controlled for by arranging questions so that a positive attitude is reflected by an 'agree' response for 12 items (items 1, 4, 6, 8, 10, 14, 16, 18, 21, 26, 28, and 30) and a 'disagree' response for the remaining 18 items (items $2,3,5,7,9,11,12,13,15,17,19,20,22,23,24,25,27$, 29). This scale was coded so that a high score would indicate a more positive attitude towards inclusion, whereas a low score would indicate a more negative attitude towards inclusion. 


\section{My Class Inventory - Short Form (Fraser, Anderson \& Walberg, 1982; Frederickson \& Monsen,}

1999): This measure is used to determine the effect of teacher attitude on the classroom learning environment that teachers provide for their pupils, according to both pupil and teacher ratings. The $\mathrm{MCl}$ investigates the classroom environment using 25 statements across scales of cohesiveness ("extent to which students know, help and are friendly towards each other"), friction ("amount of tension and quarrelling among students"), satisfaction ("extent of enjoyment of class work"), difficulty ("extent to which students find difficulty with the work of the class"), and competitiveness ("emphasis on students competing with each other", Fraser et al., 1982, p.5), with satisfactory internal consistency reported for each scale (.73 to .88) (Fraser et al., 1982).

\section{Procedure}

Ethical approval was gained through the Local Authority Research Ethics Committee. Consent for participation was gathered from schools, teachers and pupils' parents/carers. Teacher questionnaires were completed between seven and eight months after the start of the academic year.

\section{Statistical methods}

\section{Principal Components Analysis}

Exploratory Principal Components Analysis (PCA) (Tabachnick \& Fidell, 2007) was used to investigate the underlying structure and dimensionality of the items used in Section 4: Attitudes towards inclusion. 
Analyses of the items loading onto components derived from the PCA were carried out to determine the reliability of the emergent scales (Tabachnick \& Fidell, 2007).

\section{Results}

Demographic information from Section 1 of the Questionnaire from the 17 male and 66 female teachers, for whom complete data was available, revealed no gender differences (two-tailed tests) in age (range 22-59 years, mean 40.04 years, SD 10.046 years, $t(81)<1, p=.362$ ) or in teaching experience (range 5 months -36 years, mean 12.494 years, SD 10.139 years, $t(81)<1, p=.487$ ). All of the teachers reported contact with pupils with SEN. Of those for whom details were available, 32 (7 males and 25 females) reported that they had attended SEN courses while 50 (12 males and 38 females) had not done so, with no significant gender difference in attendance $\left(\chi^{2}<1, p=.824\right)$.

\section{Principal Component Analysis: Structure and Dimensionality}

Preliminary data screening of the scores from 95 teachers for the 30 items for section 4 of the Teacher's Attitudes to Inclusion Scale revealed two significant univariate outliers (Z-scores > 3.00) which were deleted, reducing the final sample size to 93. Malhalanobis distances $(p<.002)$, Cook's D values $(<1)$ and Leverage values (calculated as $\left.3^{*}(k+1) n\right)$ revealed no significant concerns regarding problematic influence.

PCA with Direct Oblimin rotation (Tabachnick \& Fidell, 2007) was carried out to examine the factorability of the screened data set. Iterative analyses were carried out excluding items with low reliability (loadings $<.40$ ) and complex structure (loadings of $>.40$ on more than one component).

The data for the final analysis was based upon 20 items and 93 teachers and met minimum standards for sampling adequacy and factorability (KMO statistic $=.873$, with individual values for all of the diagonals of the anti-image correlation matrix > .776) (Kaiser, 1974) and sphericity (Bartlett's Test $\chi 2(190)=805.179, p<.0001)$. The PCA yielded a four-factor solution with eigenvalues $>1$ 
supported by the scree plot, which accounted for $59.49 \%$ of the total variance (range of extraction communalities .488 - .697).

Intercorrelations between the components ranged from $.248-.454$, justifying the use of the Direct Oblomin oblique rotation. Final component loadings after rotation are shown in Table 1 . The items loading on these components suggests that component 1 (accounting for $38.20 \%$ of the total variance) refers to problems of inclusion of SEN pupils in mainstream classes, component 2 (accounting for $9.31 \%$ of the total variance) refers to social benefits for all of inclusion of SEN pupils in mainstream classes, component 3 (accounting for $6.48 \%$ of the total variance) refers to implications of inclusion for teaching practice, and component 4 (accounting for $5.50 \%$ of the total variance) refers to implications for teachers addressing the needs of children with SEN.

Table 1: Final Component Loadings Teachers' Attitude Towards Inclusion Scale Following Direct Oblimin Rotation ( $\mathrm{N}=93$ teachers with 20 items meeting the criteria for the final analysis)

\begin{tabular}{|c|c|c|c|c|}
\hline \multicolumn{5}{|l|}{ Rotated Component Matrix ${ }^{a}$} \\
\hline \multirow[t]{2}{*}{ Item: } & \multicolumn{4}{|c|}{ Component } \\
\hline & 1 & 2 & 3 & 4 \\
\hline $\begin{array}{l}\text { (7) It is difficult to maintain order in a normal classroom that contains an SEN } \\
\text { child }\end{array}$ & .825 & & & \\
\hline (29) SEN children are likely to create confusion in the regular classroom & .753 & & & \\
\hline $\begin{array}{l}\text { (23) Inclusion is likely to have a negative effect on the emotional development } \\
\text { of the SEN child }\end{array}$ & .690 & & & \\
\hline $\begin{array}{l}\text { (11) The SEN child probably develops academic skills more rapidly in a special } \\
\text { classroom than in a regular classroom }\end{array}$ & .636 & & & \\
\hline (9) The behaviour of SEN students sets a bad example for the other students & .555 & & & \\
\hline $\begin{array}{l}\text { (19) It is likely that an SEN child will exhibit behaviour problems in a normal } \\
\text { classroom setting }\end{array}$ & .552 & & & \\
\hline $\begin{array}{l}\text { (5) The extra attention SEN students require is to the detriment of the other } \\
\text { students }\end{array}$ & .466 & & & \\
\hline $\begin{array}{l}\text { (10) Isolation in a special class has a negative effect on the social and } \\
\text { emotional development of an SEN child }\end{array}$ & & .789 & & \\
\hline $\begin{array}{l}\text { (28) SEN students should be given every opportunity to function in the regular } \\
\text { classroom setting where possible }\end{array}$ & & .766 & & \\
\hline (21) The inclusion of SEN students can be beneficial for non-SEN students & & .746 & & \\
\hline
\end{tabular}




\begin{tabular}{|l|c|c|c|}
\hline $\begin{array}{l}\text { (18) Including the SEN child in the regular classroom promotes his or her social } \\
\text { independence }\end{array}$ & .656 & & \\
\hline $\begin{array}{l}\text { (14) Most SEN children are well behaved in the classroom } \\
\text { (27) Inclusion of SEN children necessitates extensive retraining of regular } \\
\text { classroom teachers }\end{array}$ & .653 & & \\
\hline $\begin{array}{l}\text { (13) Inclusion of SEN children requires significant change in regular classroom } \\
\text { procedures }\end{array}$ & & .814 & .523 \\
\hline $\begin{array}{l}\text { (20) Diagnostic-prescriptive teaching is better done by special education } \\
\text { teachers than by normal classroom teachers }\end{array}$ & & .492 & \\
\hline $\begin{array}{l}\text { (24) Increased freedom in the classroom creates too much confusion } \\
\text { (22) SEN children need to be told exactly what to do and how to do it }\end{array}$ & & .434 & \\
\hline $\begin{array}{l}\text { (3) A SEN child's classroom behaviour generally requires more patience from } \\
\text { the teacher than does the behaviour of a non SEN child }\end{array}$ & & & .852 \\
\hline $\begin{array}{l}\text { (12) Most SEN children do not make an adequate attempt to complete their } \\
\text { assignments }\end{array}$ & & .774 \\
\hline $\begin{array}{l}\text { (2) The needs of SEN students can best be served through special, separate } \\
\text { classes }\end{array}$ & & & .522 \\
\hline
\end{tabular}

a all loadings $<.40$ suppressed

\section{Reliability Analyses}

Reliability analyses revealed Cronbach's $\alpha$ coefficients of .86 for the seven items of Component 1

and .80 for the five items of Component 2 , indicating good reliability, together with a value of .76 for both the four items of Component 3 and for the four items of Component 4, indicating moderate reliability. No substantial increases in $\alpha$ for any of the four scales would have resulted from the elimination of additional items.

Excellent internal consistency reliability was found for each of the other sections of the TAIS, with Cronbach's alpha coefficients of.96 for teachers' willingness to include specific difficulties, and .89 for perceived adequacy of support.

\section{Demographics and the PCA components}

A series of regression analyses were carried out to investigate the effects of teachers' age, length of teaching experience, gender and attendance at SEN courses upon Anderson-Rubin factor scores from the four components arising from the PCA. Boot-strapping procedures were used on account of significant skew in teaching experience scores $(z=2.62)$. 
No significant models were observed in the case of problems of inclusion of SEN pupils in mainstream classes $(F(4,68)=1.319, p=.272)$, social benefits for all of inclusion of SEN pupils in mainstream classes $(F(4,68)=2.381, p=.060)$, or implications for teachers addressing the needs of children with $\operatorname{SEN}(F(4,68)=<1, p=.534)$. However, there was a significant model for implications of inclusion for teaching practice $(F(4,68)=3.409, p=.013)$ accounting for $11.8 \%$ of the adjusted variance, with length of teaching experience the only significant predictor $(p=.006)$, indicating that those who qualified more recently had higher scores for sensitivity to the implications of inclusion for practice in the classroom. All p-values for the other predictors were >.309.

With regard to the $\mathrm{MCl}$ scores and the demographic characteristics of the teachers, no significant bootstrapped regression models were found for composite scores for satisfaction $(F(4$, $48)=1.760, p=.152)$, friction $(F(4,48)<1, p=.889)$, competiveness $(F(4,48)<1, p=.509)$ or difficulty $(F(4,48)<1, p=.932)$. However, there was a significant model for cohesiveness $(F(4,48)=4.272$, $p=.005)$, accounting for $20.1 \%$ of the adjusted variance. Here, age $(p=.018)$ and gender $(p=.004)$ were significant predictors, indicating that younger teachers and also female teachers were more likely to self-report higher scores for cohesiveness in their classrooms.

\section{TAIS Factors and Willingness to Include}

Correlational analyses were conducted to consider the relationship between the four factors of Section 4 of the TAIS and teachers' scores for their willingness to include children with various difficulties within their inclusive class (Section 2). Factor 1 (problems of inclusion of SEN pupils in mainstream classes) was significantly correlated with teachers' willingness to include children with behavioural difficulties $(r=.247, p<.05)$, emotional difficulties $(r=.242, p<.05)$, visual difficulties $(r$ $=.211, p<.05)$, learning difficulties $(r=.293, p<.01)$, speech/language difficulties $(r=.290, p<.01)$, and multiple difficulties $(r=.248, p<.05)$, but was not correlated with willingness to include children with hearing difficulties, physical difficulties, or gifted children $(p>.05)$. 
Factor 2 (social benefits for all of inclusion of SEN pupils in mainstream classes) was significantly correlated with teachers' willingness to include children with hearing difficulties $(r=$ $.254, p<.05)$, behavioural difficulties $(r=.346, p<.001)$, emotional difficulties $(r=.430, p<.001)$, physical difficulties $(r=.323, p<.01)$, visual difficulties $(r=.425, p<.001)$, learning difficulties $(r=$ $.502, p<.001)$, speech/language difficulties $(r=.441, p<.001)$, and multiple difficulties $(r=.408, p<$ $.001)$, but was not correlated with teachers' willingness to include gifted children ( $p>.05)$.

Factor 3 (implications of inclusion for teaching practice) was not significantly correlated with teachers' willingness to include any of the types of difficulties, $p>.05$.

Factor 4 (implications for teachers addressing the needs of children with SEN) was significantly correlated with teachers' willingness to include children with behavioural difficulties ( $r=$ $.211, p<.05)$ and learning difficulties $(r=.222, p<.05)$, but was not correlated with any of the other types of difficulties $(p>.05)$.

\section{TAIS Factors and Adequacy of Support}

Regression analyses were conducted to consider the four factors and teachers' perception of adequacy of support to include children with special educational needs within their classroom (Section 3). The four factors were entered as independent variables into the model, and adequacy of support as the dependent variable. Although a significant model was found $(F(4,84)=3.03, p<.05)$, none of the independent factors significantly predicted teachers' perceived adequacy of support scores $(p>.05)$.

\section{TAIS Factors and Teacher $\mathrm{MCl}$ scores}

Correlational analyses (all two-tailed) revealed moderate but significant negative correlations between $\mathrm{MCl}$ scores for satisfaction and friction $(r=-.390, p<.01)$ and friction and cohesiveness $(r=-$ $.374, p<.01)$, and also a positive correlation between satisfaction and cohesiveness $(r=.484, p<.01)$. 
Regression analyses were conducted to consider how the four factors of the Section 4 of the TAIS related to teacher ratings of their classroom environment. As there was no reason to assume that any of the factors were more likely to predict teacher classroom environment ratings than others, all four factors were entered into the regression within the same model. Separate regression analyses were considered for each of the five subscales of the $\mathrm{MCl}$. The second factor, 'social benefits for all of inclusion of SEN pupils in mainstream classes', was found to predict teacher ratings of pupil satisfaction within the classroom (see Table 2) and to predict teacher ratings of pupil cohesiveness within the classroom (see Table 3). This factor did not predict teacher ratings of friction, competitiveness, or difficulty (all p-values > .05). The other 3 factors of the TAIS were not found to predict any of the subscales of teacher ratings of classroom environment (all p-values $>.05$ ).

Table 2: Multiple regression analysis to consider the relationship between the four factors of the TAIS and teacher rating of pupil satisfaction in their classroom environment

\begin{tabular}{cccc}
\hline & B & Std. Error & $\beta$ \\
\hline Model 1 & & & \\
(Constant) & 13.167 & .208 & \\
Factor 1 & .097 & .251 & .048 \\
Factor 2 & .681 & .233 & $.339^{*}$ \\
Factor 3 & .176 & .210 & .094 \\
Factor 4 & .329 & .239 & .172 \\
\hline
\end{tabular}

Note: $\mathrm{R}^{2}=.220(* \mathrm{p}<.01)$

Table 3: Multiple regression analysis to consider the relationship between the four factors of the TAIS and teacher rating of pupil cohesiveness in their classroom environment

\begin{tabular}{lccc}
\hline & B & Std. Error & $\beta$ \\
\hline Model 1 & & & \\
(Constant) & 9.610 & .314 & \\
Factor 1 & .494 & .378 & .171
\end{tabular}




\begin{tabular}{llll} 
Factor 2 & .731 & .350 & $.258^{*}$ \\
Factor 3 & .256 & .317 & .097 \\
Factor 4 & -.301 & .360 & -.112 \\
\hline
\end{tabular}

Note: $\mathrm{R}^{2}=.114\left({ }^{*} \mathrm{p}<.05\right)$

\section{Discussion}

The factor structure of the Teacher Attitudes to Inclusion Scale (TAIS) suggest that this revised version shows great promise as a valid and reliable measure of teacher attitude to inclusion for both research and applied purposes. The principal component analysis for Section 4 of the TAIS revealed a different factor structure compared with the original ORMs scale. The ORMs had five components of "general philosophy of mainstreaming", "classroom behaviour of special needs children", "perceived ability to teach the special needs child", "classroom management with special needs children", and "academic and social growth of the special needs child" (Larrivee, 1982). However, the PCA for Section 4 of the TAIS revealed four-factors of "problems of inclusion of SEN children in mainstream classes", "social benefits for all of the inclusion of SEN pupils in mainstream classes", "implications of inclusion for teaching practice", and "implications for teachers addressing the needs of children with SEN". This factor structure of Section 4 of the revised TAIS is both more parsimonious and, following Avramidis, Bayliss and Burden (2000), more reflective of issues relating to inclusion. The measure had moderate to good internal consistency for each component, with results similar to those of the original Opinions Relative to Mainstreaming Scale (Larrivee and Cook, 1979). The additional sections in the revised scale show excellent internal consistency, and provide further credibility for the revised TAIS. For instance, in addition to determining teachers' attitudes towards inclusion, the 'willingness to include' section provides information regarding types of special educational needs and disabilities that teachers are willing to have in their class.

The usability of the TAIS has been demonstrated through the use of two large-scale independent samples based in both New Zealand (Monsen \& Frederickson, 2004) and in England 
(Monsen, Ewing \& Kwoka, 2013). These studies considered the impact of teacher attitudes towards inclusion on type of classroom learning and social-emotional environment provided for pupils, and found that teachers with high attitude scores were more likely to provide classroom environments that were more facilitating for SEN pupils compared with teachers with low attitude scores (Monsen \& Frederickson, 2004; Monsen et al., 2013). The current paper considers the relationship of the factors of Section 4 of the TAIS with the subscales of the My Class Inventory. The findings suggest that teacher scores on the second factor of "social benefits for all of the inclusion of SEN pupils in mainstream classes" significantly predict teacher ratings of pupil satisfaction and cohesion within the classroom environment. In addition, the first, second, and fourth factors were found to be correlated with teachers' willingness to include children with a range of difficulties within their classroom. Interestingly these factors were not correlated with willingness to include gifted children, or in the case of the first factor, children with hearing or physical difficulties. This may suggest that teachers do not foresee so many implications for including children with these difficulties in comparison with difficulties such as behavioural, emotional or learning difficulties. These findings provide further evidence of the validity of the TAIS.

Further research could compare the results of the TAIS questionnaire across cultures with differing levels of inclusion, for example, comparing Iceland, where children with SEN are fully included within mainstream schools, with countries such as Japan, Nigeria or China where there is relatively low inclusion of children with SEN. Future uses for the TAIS include studying the effect of teacher attitudes on a range of variables, with the aim of generating a fuller picture of the factors which influence teacher willingness to include SEN pupils. This knowledge could then be used to systematically look at functional ways of supporting classroom practitioners to meet the needs of an increasingly diverse range of learners. Future research may benefit from the use of more systematic sampling, such as by sampling according to different age groups or Key Stages taught, or by considering differences in teachers' attitudes across infant, junior and secondary schools, so that these groups can be compared. In addition, the current study did not look specifically at pupils with 
Statements of Special Educational Needs, but rather considered a random sample of mainstream classrooms which included pupils with SEN. Although this enabled the current study to consider teacher attitudes at a global level, it would also be useful to consider a specific sample of teachers specifically working with pupils with SEN statements. A limitation of the current study is that it relied on teacher and pupil self-reports, and did not consider other sources, such as parents/carers, or other indicators of classroom environment, such as pupil achievement or attainment. Future research may therefore benefit from additionally considering these sources.

In conclusion, the TAIS reported in this paper has been shown to be a robust and easily administered measure of teacher attitude to inclusion. It is shared in the hope that other researchers and applied practitioners will extend its use so that a fuller picture of the complex factors influencing teacher attitude to inclusion can be further clarified. The ultimate aim is to then design and implement supportive approaches which enable all teachers to work effectively with a diverse range of learners within mainstream settings.

\section{Author Note}

A copy of the TAIS measure is available from the authors on request. 


\section{References}

Antonak, R.F., \& Larrivee, B. (1995). Psychometric analysis and revision of the opinions relative to mainstreaming scale. Exceptional Children, 62(2), 139-149.

Avramidis, E., Baylis, P., \& Burden, R. (2000). A survey into mainstream teachers' attitudes towards the inclusion of children with special educational needs in the ordinary school in one local education authority. Educational Psychology, 55(2), 191-211.

Beattie, J.R., Anderson, R.J., \& Antonak, R.F. (1997). Modifuing attitudes of prospective educators toward students with disabilities and their integration into regular classrooms. The Journal of Psychology: Interdisciplinary and Applied, 131(3), 245-259.

Cohen, J (1992). "A power primer". Psychological Bulletin, 112 (1),155-159.

Department for Children, Schools and Families (DCSF) (2010). Evaluation of impact of DCSF investment in initiatives designed to improve teacher workforce skills in relation to SEN and disabilities: The first 6 months. London, UK: DCSF.

Department for Education (2011, March 11). SEN and disability Green Paper: Executive Summary. Department for Education. Retrieved from http://www.education.gov.uk

Department for Education and Skills (DfES) (2001) Inclusive schooling: Children with special educational needs. Nottingham, UK: DfES.

Department for Education and Skills (DfES) (2003). Every Child Matters. London, UK: The Stationery Office.

Department for Education and Skills (DfES) (2004). Inclusion and Pupil Achievement. Nottingham, UK: DfES.

Department for Education and Skills (DfES) (2006). Preventing Social Exclusion of Disabled Children and Their Families. Nottingham, UK: DfES.

Evans, J., \& Lunt, I. (2002). Inclusive education: Are there limits? European Journal of Special Needs Education, 17(1), 1-14.

Forlin, C., Keen, M., \& Barrett, E. (2008). The concerns of mainstream teachers: Coping with inclusivity in an Australian context. International Journal of Disability, Development and Education, 55(3), 251-264.

Frederickson, N., \& Cline, T. (2010). Special Educational Needs, Inclusion and Diversity. Second Edition. Berkshire, UK: McGraw-Hill.

Gibb, K., Tunbridge, D., Chua, A., \& Frederickson, N. (2007). Pathways to inclusion: Moving from special school to mainstream. Educational Psychology in Practice, 23, 109-127. 
Goodman, R. L., \& Burton, D. M. (2010). The inclusion of students with BESD in mainstream schools: Teachers' experiences of and recommendations for creating a successful inclusive environment. Emotional and Behavioural Difficulties, 15, 223-237.

Grieve, A.M. (2009). Teachers' beliefs about inappropriate behaviour: challenging attitudes? Journal of Research in Special Educational Needs, 9(3), 173-179.

Hill, F., \& Parsons, L. (2000). Teamwork in the Management of Emotional and Behavioural Difficulties. London, UK: David Fulton.

Janney, R.E., \& Snell, M.E. (2006). Modifying schoolwork in inclusive classrooms. Theory into Practice, 45(3), 215-223.

Larrivee, B. (1982). Factors underlying regular classroom teachers' attitude toward mainstreaming. Psychology in the Schools, 19(3), 374-379.

Larrivee, B., \& Cook, L. (1979). Mainstreaming: A study of the variables affecting teacher attitude. Journal of Special Education, 13(3), 315-324

Monsen, J.J., \& Frederickson, N. (2004). Teachers' attitudes towards mainstreaming and their pupils' perceptions of their classroom learning environment. Learning Environments Research, 7, 129142.

Monsen, J.J., Ewing, D.L., \& Kwoka, M. (2013). Teachers' attitudes towards inclusion, perceived adequacy of support and classroom learning environment. DOI 10.1007/s10984-013-9144-8.

Ross-Hill, R. (2010). Teacher attitude towards inclusion practices and special needs students. Journal of Research in Special Educational Needs, 9(3), 188-198.

Tabachnick, B.G. \& Fidell, L.S., (2007). Using multivariate statistics (5th Ed.). Boston: Allyn and Bacon.

UNESCO. (1994). The Salamanca statement and framework for action on special needs education. Paris, France: UNESCO.

Visser, J., Cole, T., \& Daniels, H. (2003). Inclusion for the difficult to include. Support for Learning, 17(1), 23-26.

Visser, J., \& Stokes, S. (2003). Is education ready for the inclusion of pupils with emotional and behavioural difficulties: A rights perspective? Educational Review, 55(1), 65-75. 